\title{
Genetic risk factors for autoimmune hepatitis: implications for phenotypic heterogeneity and biomarkers for drug response
}

\author{
Takashi Higuchi $i^{1,2,3}$, Shomi Oka $a^{1,3,4}$, Hiroshi Furukawa ${ }^{1,3,4^{*}}$ (D), Shigeto Tohma ${ }^{3,4}$, Hiroshi Yatsuhashi ${ }^{5}$ and \\ Kiyoshi Migita ${ }^{5,6}$
}

\begin{abstract}
Autoimmune hepatitis (AlH) is a rare chronic progressive liver disease with autoimmune features. It mainly affects middle-aged women. AlH is occasionally complicated with liver cirrhosis that worsens the prognosis. Genetic and environmental factors are involved in the pathogenesis of $\mathrm{AlH}$. Genetic studies of other diseases have been revealing of pathogenesis and drug efficacy. In this review, we summarize the genetic risk factors for AlH, including human leukocyte antigen (HLA) and non-HLA genes. A genome-wide association study (GWAS) on European AlH revealed the strongest associations to be with single nucleotide variants (SNVs) in HLA. Predisposing alleles for AlH were $D R B 1^{*} 03: 01$ and $D R B 1^{* 04}$ :01 in Europeans; DRB1*04:04, DRB1*04:05, and DRB1*13:01 in Latin Americans; and $D R B 1{ }^{*} 04: 01$ and $D R B 1^{*} 04: 05$ in Japanese. Other risk SNVs in non-HLA genes for AlH were found by a candidate gene approach, but several SNVs were confirmed in replication studies. Some genetic factors of AlH overlapped with those of other autoimmune diseases. Larger-scale GWASs of other ethnic groups are required. The results of genetic studies might provide an explanation for the phenotypic heterogeneity of $\mathrm{AlH}$ and biomarkers for drug responses.
\end{abstract}

Keywords: Autoimmune hepatitis, Genetic risk factor, HLA, Single nucleotide variant, Liver cirrhosis

\section{Introduction}

Autoimmune hepatitis (AIH) is a chronic progressive autoimmune liver disease which mainly affects middleaged women [1-6]. Among adult AIH patients, 70-90\% were female and the peak age of onset was $60-80$ years $[7,8]$. AIH is a rare disease; its prevalence is $8-24.5$ per 100000 in European populations [7]. In Asia, its prevalence is similar $[8,9]$. AIH is characterized by elevated levels of aspartate aminotransferase, alanine aminotransferase, or

\footnotetext{
* Correspondence: furukawa-tky@umin.org

'Molecular and Genetic Epidemiology Laboratory, Faculty of Medicine, University of Tsukuba, 1-1-1 Tennodai, Tsukuba 305-8575, Japan

${ }^{3}$ Department of Rheumatology, National Hospital Organization Tokyo National Hospital, 3-1-1 Takeoka, Kiyose 204-8585, Japan

Full list of author information is available at the end of the article
}

immunoglobulin $\mathrm{G}$ and the presence of interface hepatitis. The production of antinuclear antibodies in serum and anti-smooth muscle antibodies has been observed in type 1 $\mathrm{AIH}$. Type $1 \mathrm{AIH}$ shares features with systemic lupus erythematosus (SLE): the presence of lupus erythematosus cells and antinuclear antibodies. Thus, type $1 \mathrm{AIH}$ was initially termed "lupoid hepatitis" [10-12]. AIH with liver kidney microsomal type 1 antibodies was designated type 2 $\mathrm{AIH}$ and was observed in European children. The diagnosis of AIH is often complicated by the presence of liver cirrhosis, and the pattern of progression in these patients is smoldering and latent. AIH patients diagnosed with liver cirrhosis are at higher risk of developing hepatocellular carcinoma [13]. The prognosis of AIH patients with cirrhosis was worse than for those without. In a Japanese study, the 
15-year hepatocellular carcinoma-free survival rate was $62.2 \%$ for $\mathrm{AIH}$ with cirrhosis, compared with $96.6 \%$ for $\mathrm{AIH}$ without cirrhosis [14]. Although most $\mathrm{AIH}$ patients present a chronic and progressive course, some show acute presentation $[15,16]$, indicating that $\mathrm{AIH}$ is a heterogeneous syndrome. The criteria of the International Autoimmune Hepatitis Group (IAIHG) for the diagnosis of AIH were developed from clinical, laboratory (including the human leukocyte antigen $[H L A]$ allele), and pathological findings [17].

Although the etiology of AIH is obscure, it is supposed that environmental and genetic factors are involved in its pathogenesis. The role of gene-environment interactions has also been predicted in autoimmune diseases [18]. Viral infections, low levels of vitamin D, altered microbiota, exposure to sex hormones, and the administering of drugs are candidate environmental factors in an individual's predisposition to AIH. Infection by several viruses, including hepatitis $C$ virus, cytomegalovirus, and herpes simplex virus type 1 , are thought to cause AIH according to the molecular mimicry hypothesis [19]: self-antigens sharing amino acid sequence homologies with virus proteins would be the targets of autoimmune reactions. Low serum vitamin D levels are associated with severe histological findings of AIH [20]. Increased intestinal permeability, dysregulation of microbiota, and bacterial translocation have been noted in AIH patients [21]. AIH predominantly affects females, and the effects of sex hormones have been shown to be similar in other autoimmune diseases [22, 23]. Drug- induced hepatitis is classified separately from AIH. However, exposure to drugs remains a possible cause of $\mathrm{AIH}$ [24]. Since a risk of drug-induced liver injury has also been associated with HLA [25-30], similar mechanisms may be involved in the pathogenesis of $\mathrm{AIH}$ during unrecognized exposure to drugs.

A concordance of AIH in twins and AIH family accumulation were evident in a recent epidemiological study, and extrahepatic autoimmune diseases have been frequently observed in AIH patients [31-33], suggesting common genetic risk factors for $\mathrm{AIH}$ and other autoimmune diseases. Although $H L A$ is the strongest genetic risk factor for $\mathrm{AIH}$, other genetic factors associated with non-HLA genes have also been reported (Table 1). Since genetic studies have contributed in revealing the mechanisms of pathogenesis and drug efficacy for other diseases, genetic risk factors for $\mathrm{AIH}$ including $H L A$ and non-HLA genes are summarized in this review.

\section{HLA genes}

A genome-wide association study (GWAS) is an association study of a genome-wide set of single nucleotide variants (SNVs) to find the contribution of common variants to susceptibility to disease. A GWAS of type $1 \mathrm{AIH}$ was performed on European populations and a sole significant association for SNV in the HLA region was detected, indicating $H L A$ as the strongest genetic risk factor for AIH [34]. In $H L A$ association studies, $D R B 1 * 03: 01$ and $D R B 1 * 04: 01$ were associated with $\mathrm{AIH}$ in European populations [35]. It has been reported that

Table 1 Susceptibility genes of type $1 \mathrm{AlH}$

\begin{tabular}{|c|c|c|c|}
\hline & Susceptibility genes or alleles (protective alleles are underlined) & Populations & References \\
\hline GWAS & $D R B 1 * 03: 01, D R B 1 * 04: 01, S H 2 B 3, C A R D 10$ & European & {$[34]$} \\
\hline \multirow[t]{16}{*}{ Candidate gene approach } & $D R B 1 * 03: 01, D R B 1 * 04: 01, \underline{D R B 1 * 15: 01}$ & European & {$[35-38]$} \\
\hline & $D R B 1 * 04: 01, D R B 1 * 04: 05, \underline{D R B 1 * 13: 02}, \underline{D R B 1 * 15: 01}, D R B 1 * 04 / D R B 1 * 08$ & Japanese & {$[39-44]$} \\
\hline & $D R B 1 * 04: 04, D R B 1 * 04: 05, D R B 1 * 13: 01, \underline{D R B 1 * 13: 02}$ & Hispanic & {$[45-51]$} \\
\hline & $D R B 1 * 04: 05$ & Korean & {$[52]$} \\
\hline & $D R B 1 * 01, D R B 1 * 04, D R B 1 * 08, D R B 1 * 14$ & Indian, Iranian & {$[53-55]$} \\
\hline & $D R B 1^{*} 13, D R B 1 * 14$ & Pakistani & {$[56]$} \\
\hline & DP5 (rs9277534G) & Japanese & {$[57]$} \\
\hline & $K I R$ & European & {$[58,59]$} \\
\hline & PTPN22 & Japanese & {$[60]$} \\
\hline & $\mathrm{SH} 2 \mathrm{~B} 3$ & Japanese & {$[61]$} \\
\hline & TNFAIP3 & Japanese & {$[62]$} \\
\hline & STAT4 & Japanese & {$[63]$} \\
\hline & TNIP1 & Japanese & {$[64]$} \\
\hline & CTLA4, ICOS & European, Japanese & {$[65-67]$} \\
\hline & FAS & European, Japanese & {$[68,69]$} \\
\hline & TNF & European & {$[70,71]$} \\
\hline
\end{tabular}


$D R B 1 * 04: 04, D R B 1 * 04: 05$, and $D R B 1 * 13: 01$ are associated with $\mathrm{AIH}$ in Latin America [45-48]. DRB1*04:01 and $D R B 1 * 04: 05$ are associated with $\mathrm{AIH}$ in Japanese populations [39-42]. DRB1*08:02 and DRB1*08:03 also indicate predisposition to $\mathrm{AIH}$ in Japanese populations, when these alleles are possessed by individuals with $D R B 1 * 04: 05$ [42]. The associations of the DRB1 heterozygous genotypes have also been reported for type 1 diabetes [72]. These associations in type 1 diabetes have been explained by the possible role of transcomplementing DQ $\alpha-\beta$ heterodimer molecules, because of the strong linkage disequilibrium between $D R$ and $D Q$ loci. These molecules are composed of proteins encoded by the $D Q A 1$ of one haplotype and the $D Q B 1$ of the other. Analogically, the associations of the $D R B 1$ heterozygous genotypes in AIH can also be explained by the possible role of trans-complementing DQ $\alpha-\beta$ heterodimer molecules. DRB1*04:05 has also been associated with AIH in Korean populations [52]. DRB1*01, $D R B 1 * 03, D R B 1 * 04, D R B 1 * 08, D R B 1 * 13$, and $D R B 1 * 14$ have been associated with $\mathrm{AIH}$ in Indian and Iranian populations [53-55]. DRB1*13 and $D R B 1 * 14$ have been associated with AIH in Pakistani populations [56]. Although $\mathrm{AIH}$ patients possessing DRB1*04 were predominantly female in European populations [73], this was not confirmed in our previous study [42].

$D R B 1 * 15: 01$ has been protectively associated with $\mathrm{AIH}$ in European and Japanese populations [35, 39]. $D R B 1 * 13: 02$ has also been seen to be protective against AIH in Latin America [46, 48, 49] and Japan [41]. However, $D R B 1 * 13: 02$ and $D R B 1 * 13: 01$ differ by only a single amino acid residue. $D R B 1 * 13: 02$ is known to be a common protective allele against several autoimmune diseases [74].

Type 2 AIH has been observed in European female children, but only a few studies have been conducted because of the low prevalence of the disease. $D R B 1 \% 03$ and $D R B 1 * 07$ have been reported to be associated with risk of type 2 AIH [50, 75].

It has also been reported that an SNV in DPB1, rs9277534, is associated with AIH in Japanese populations [57]. The rs9277534G variant is known to be associated with the expression levels of DPB1 [76, 77] and also shows strong linkage disequilibrium with DP5 alleles (DPB1*03:01, DPB1*05:01, DPB1*06:01, DPB1*09: 01, $D P B 1 * 13: 01, D P B 1 * 14: 01, D P B 1 * 19: 01$, and $D P B 1 * 25$ : 01) [57, 78, 79]. Similarly, the DP5 allele group was found to be associated with AIH in our analyses (Supplementary Table S1, unpublished), and DP5 tended to be associated with risk of $\mathrm{AIH}$, when conditioned on $D R B 1$ alleles. On the other hand, $D P B 1 * 04: 01$ tended to be associated with the risk of $\mathrm{AIH}$ including cirrhosis (Supplementary Table S2, unpublished) and also exhibited this tendency of association when conditioned on
$D R B 1$ alleles. These data suggest differing specificities of DPB1 alleles between AIH per se and AIH with cirrhosis, confirming the heterogeneity of AIH.

\section{Non-HLA genes}

The previous GWAS on European type 1 AIH also suggested associations of SNVs in HLA, CARD10, SH2B3, and ICOS [34]. The association between rs6000782 in CARD10 and $\mathrm{AIH}$ was not observed in a replication study in Japanese populations [80]. CARD10 is a scaffold protein and plays a critical role in the activation of the nuclear factor- $\mathrm{kB}(\mathrm{NF}-\mathrm{kB})$ pathway [81]. Although the reported SNV (rs3784504) is not polymorphic in Japanese populations, another SNV (rs11065904) in SH2B3 was found to be associated with Japanese AIH [61]. SH2B3 is an adaptor protein regulating cytokine signaling and a negative regulator of $\mathrm{T}$ cell activation. This SNV may change the expression levels of the $S H 2 B 3$ gene. The reported SNV (rs3784504) in the GWAS is an SNV associated with celiac disease [82] and is also a protective factor against bacterial infection [83]. The SNV rs4325730, upstream of ICOS, was associated with AIH in a replication study in Japanese populations [65]. This SNV is in strong linkage disequilibrium with an SNV associated with celiac disease, rs4675374 [84, 85]. It has been reported that ICOS-deficient mice exhibit reduced germinal center formation [86]. Altered expression levels of ICOS molecules may change the development of autoreactive $\mathrm{B}$ cells via $\mathrm{T}$ follicular helper cells. Thus, some of the results from the GWAS have been confirmed in replication studies, and some risk SNVs of $\mathrm{AIH}$ were found to be common with those of celiac disease.

The candidate gene approach on type $1 \mathrm{AIH}$ has been performed on several genes. Variants among the $C D 28$, CTLA4, and ICOS gene clusters in $2 \mathrm{q} 33.2$ have been reported to be associated with autoimmune or inflammatory diseases. The products of CD28, CTLA4, and ICOS genes were CD28-family member molecules transducing co-stimulatory or inhibitory signals. An SNV (+49A/G) in the CTLA4 gene is associated with AIH in European populations $[66,67]$, but this association was not confirmed in other studies $[87,88]$. A meta-analysis of the SNV on AIH produced no significant associations [89]. An SNV (-670) upstream of the FAS gene is associated with AIH in Japanese populations [68] and is associated with $\mathrm{AIH}$ patients with cirrhosis at presentation in European populations [69]. The expression of Fas molecules on the cell surface leads to programmed cell death. The role of the FAS gene in AIH is supported by the results from animal models; Fas-deficient mice are less sensitive to Concanavalin A-induced hepatitis, an AIH animal model [90, 91]. An SNV (-308) in the TNF gene is associated with $\mathrm{AIH}$ in European populations [70, 71] and 
increases the serum levels of TNF- $\alpha$, a proinflammatory cytokine [92]. An SNV (rs755622) in the promoter region of the MIF gene is associated with AIH severity in Japan and the USA [93]. MIF is a proinflammatory cytokine implicated in the pathogenesis of autoimmune diseases. An SNV (-590) in the promoter region of the IL4 gene has been associated with pediatric AIH in Egypt [94]. IL-4 is a cytokine and induces a T helper 2 response. An SNV (rs7574865) in STAT4 is associated with AIH in Japanese populations [63], and has been reported to be associated with various autoimmune diseases, including SLE [95]. STAT4 is a transcription factor activated by IL-12, leading to the activation of monocytes and to T helper 1 and $\mathrm{T}$ helper 17 cell differentiation; it is considered to play an important role in liver injury [96]. An SNV (rs2476601) in PTPN22 is associated with various autoimmune diseases in European populations. This SNV is not polymorphic in Japanese populations. However, other SNVs (rs1217412, rs1217388, rs1217407, and rs2488458) in PTPN22 are associated with Japanese AIH [60]. Lymphoid-specific protein tyrosine phosphatase is encoded by PTPN22 and plays an important role in regulation of the activation of T cells.

An SNV (exon 2, restriction fragment length polymorphism with Fok I) in the VDR gene is associated with AIH in European and Chinese populations [97, 98]. Variants of the VDR gene are associated with various autoimmune diseases $[99,100]$. Vitamin D receptor is encoded by the $V D R$ gene and 1,25-dihydroxyvitamin $D_{3}$, the active form of vitamin $\mathrm{D}$, inhibits the production of cytokines by T cells [101]. An SNV (-1993) in the promoter region of the $T B X 21$ gene is associated with AIH in Chinese populations [102]. T-bet is encoded by the $T B X 21$ gene and is a regulator of the development of T helper 1 cells. SNVs $(+869$ and +915$)$ in the exon 1 of the TGFB1 gene are associated with AIH severity in Latin America [103]. These variants are associated with the production of TGF- $\beta 1$, which causes tissue fibrosis.

TNFAIP3 is a common susceptibility gene for autoimmune diseases, including SLE $[104,105]$. A20 is encoded by the TNFAIP3 gene and an inhibitor of the NF- $\mathrm{kB}$ signaling pathway. It has been reported that deleterious missense variants or loss of function variants in the TNFAIP3 gene causes haploinsufficiency of A20 syndrome [106-108], an autoinflammatory disease with symptoms similar to those of Behçet's disease. Deleterious missense variants change amino acid residues conserved across species. Deleterious SNVs in the exons of the TNFAIP3 gene are associated with AIH patients with cirrhosis in Japanese populations [62]. In addition, the deleterious allele frequency of TNFAIP3 increases in AIH patients without the DRB1 risk alleles (DRB1*04:01, $D R B 1 * 04: 05, D R B 1 * 08: 02$, or $D R B 1 * 08: 03$ ) [42]. It has also been reported that A20 attenuates liver cirrhosis in nonalcoholic fatty liver disease [109], and that SNVs in TNFAIP3 are associated with the severity of liver cirrhosis in patients with the human immunodeficiency virus and hepatitis $C$ virus [110].

SNVs in the TNIP1 gene are associated with SLE [111-113]. An adaptor protein binding to A20 is encoded by TNIP1 and inhibits NF- $\mathrm{kB}$ activation by TNF- $\alpha$. An SNV, rs7708392, in the TNIP1 gene is associated with AIH in Japanese populations [64]. A stronger association is observed in AIH patients without the $D R B 1 * 04: 05$ allele, the strongest genetic risk factor for Japanese AIH.

Some HLA class I molecules are the ligands of the killer cell immunoglobulin-like receptors (KIRs) transducing inhibitory or activating signals. Age at onset of type $1 \mathrm{AIH}$ is significantly associated with the KIR2DS1 gene in European populations [58]. The increased frequency of the functional form of KIR2DS4 in pediatric type 1 $\mathrm{AIH}$ has been detected and a synergistic effect observed in combination with $D R B 1 * 13: 01$ in Latin America [59].

Attempts have been made to explain the female predominance in autoimmune diseases by genetic factors: skewed X chromosome inactivation, $\mathrm{X}$ chromosome dosage, or microchimerism [114]. When $\mathrm{X}$ chromosome inactivation is skewed, $\mathrm{X}$-linked antigens may escape presentation in the thymus. The increased incidence of autoimmune diseases has been observed in cases of Turner syndrome (45, X monosomy) and Klinefelter syndrome (47, XXY trisomy). Fetal stem cells enter the blood circulation of the mother during birth and microchimerism develops. Microchimeric cells may be targets as non-self cells. However, few studies have been published of these factors in AIH. There is only one single report on a Klinefelter syndrome patient with SLE and AIH [115].

\section{Conclusions and future perspectives}

Although the influence of many genetic and environmental factors on the pathogenesis of AIH has been investigated, only some have been confirmed as risk factors for AIH. DRB1 is the sole established genetic risk factor. Because the possession of DRB1*03 or DRB1*04 is included in the criteria of the International Autoimmune Hepatitis Group for diagnosis of type I AIH [17], the allele carrier frequencies of these alleles should be found to be greater in AIH patients. Although the effects may be limited, the influence of the risk DRB1 alleles seems to have been overestimated. The effect of $D R B 1$ on the pathogenesis of $\mathrm{AIH}$ has been highlighted. However, $D R B 1$ and $D Q B 1$ are in strong linkage disequilibrium and the role of $D Q B 1$ in predisposition cannot be eliminated [42]. It is of interest that some SNVs in non-HLA genes are associated with $\mathrm{AIH}$ patients 
without the risk DRB1 alleles [62, 64]. These data suggest that the weaker genetic risk factors in non-HLA genes cannot contribute to the predisposition to $\mathrm{AIH}$ of individuals with the other genetic risk factor when the gene-gene interaction is observed in AIH patients. Additionally, the clinical features of AIH patients with $D R B 1 * 04: 05$ differ from those without it [40, 42]. Thus, genetic analyses of AIH may provide an explanation for the heterogeneity of AIH.

Since type $1 \mathrm{AIH}$ shares some clinical features with SLE [10-12], common susceptibility genes were to be expected between SLE and AIH. HLA, STAT4, TNIP1, TNFAIP3, and PTPN22 were the common susceptibility genes detected between SLE and AIH. There were also some common predisposing genes detected between AIH and celiac disease: HLA, SH2B3, ICOS, TNFAIP3, and STAT4 [82]. These data also suggest the existence of common signaling pathways in the pathogenesis of $\mathrm{AIH}$ and celiac disease. The associated alleles and the association manner of HLA in AIH were similar to those in type 1 diabetes, but not to those in rheumatoid arthritis [42]. Thus, some genetic factors of AIH seem to overlap with those of some autoimmune diseases.

The results from several GWASs should be reported, to estimate the similarity of the genetic factors. There has been only one GWAS on AIH [34], although many GWASs have been published on other diseases. In that one GWAS, significant associations of SNVs were found only in the $H L A$ region. Some suggestive associations of SNVs with AIH were observed in non-HLA genes. Since $\mathrm{AIH}$ is a rare disease, it is quite difficult to enlarge the sample size of the GWAS. Because it is also a heterogeneous disease, a larger sample size is needed to detect the association of SNVs in non-HLA genes. Although many genes have been reported to be associated with $\mathrm{AIH}$ in different ethnic populations by the candidate gene approach, the GWAS could not confirm this. Different allele frequencies in different ethnic populations, the small sample size, the effects of various environmental factors, and the heterogeneity of the disease are the reasons for this result. A multi-ethnic, large-scale casecontrol study is needed to resolve the problem [116]. Such future studies on AIH are eagerly awaited, to shed light on its pathogenesis. The results of these GWASs should show a similarity between AIH and other autoimmune diseases [117]. However, a GWAS can detect the contributions only of common variants, not those of rare variants, structural variants, copy-number variants, gene families, gene-gene interactions, or gene-environment interactions. Some AIH patients present more complicated cases because of the accompaniment of cirrhosis, and their prognoses are worse [14]. SNVs specifically associated with AIH with cirrhosis have been detected (Supplementary Table S2) [62, 69] and may predict the prognosis of the patients. More than $80 \%$ of AIH patients respond to conventional treatments with corticosteroid, but less than $20 \%$ are refractory $[13,118]$. Some genetic biomarkers for the prediction of the response to conventional treatments may be detected by analogy in the future, to establish a new strategy for the treatment of AIH.

The genetic analyses of AIH revealed the risk SNVs in $H L A$ and non- $H L A$ genes. Several susceptible genes have been confirmed so far. Although it is difficult to increase the sample size for this rare disease, larger-scale GWASs of different ethnic groups with precise clinical information are necessary, to confirm these susceptible genes and to clarify the gene-gene and gene-environment interactions. Additionally, genetic factors of AIH overlapped with those of other autoimmune diseases, suggesting an overlap of pathogenesis. Stratified analyses of AIH may clarify variations in the pathogenesis of disease subtypes and explain the obvious heterogeneity of AIH. In the near future, discrimination of treatment responders could be predicted by biomarkers generated from genetic analyses of $\mathrm{AIH}$.

\section{Supplementary Information}

The online version contains supplementary material available at https://doi. org/10.1186/s40246-020-00301-4.

Additional file 1: Supplementary Table S1. Logistic regression analysis of DPB1 alleles in AlH patients and controls.

Additional file 2: Supplementary Table 2. Logistic regression analysis of DPB1 alleles in AlH patients with cirrhosis and controls.

\section{Abbreviations}

AlH: Autoimmune hepatitis; GWAS: Genome-wide association study; HLA: Human leukocyte antigen; IAlHG: International Autoimmune Hepatitis Group; KIRs: Killer cell immunoglobulin-like receptors; NF-kB: Nuclear factorKB; SNVs: Single nucleotide variants; SLE: Systemic lupus erythematosus

\section{Acknowledgements}

The members of the NHO-AlH study group are Kiyoshi Migita (Fukushima Medical University School of Medicine), Hideo Nishimura (NHO Asahikawa Medical Center), Hironori Sakai (NHO Beppu Medical Center), Toshihiko Kaneyoshi (NHO Fukuyama Medical Center), Eiichi Takezaki (NHO Higashi Hiroshima Medical Center), Noboru Hirashima and Hironao Takahashi (NHO Higashi-nagoya National Hospital), Noriaki Naeshiro (NHO Higashi-hiroshima Medical Center), Yukio Oohara (NHO Hokkaido Medical Center), Hajime Ohta (NHO Kanazawa Medical Center), Takeaki Sato (NHO Kokura Medical Center), Kazuhiro Sugi (NHO Kumamoto Medical Center), Hiroshi Kouno (NHO Kure Medical Center and Chugoku Cancer Center), Motoyuki Kohjima and Makoto Nakamuta (NHO Kyushu Medical Center), Michio Kato and Iwao Yabuuchi (NHO Minami Wakayama Medical Center), Minoru Nakamura, Seigo Abiru, Sung Kwan Bae, Shigemune Bekki, Satoru Hashimoto, Hiromi Ishibashi, Yuka Jiuchi, Atsumasa Komori, Shinya Nagaoka, Masashi Ohtani, Katsumi Yamasaki, and Hiroshi Yatsuhashi (NHO Nagasaki Medical Center), Masaaki Shimada (NHO Nagoya Medical Center), Fujio Makita (NHO Shibukawa Medical Center), Toyokichi Muro (NHO Oita Medical Center), Haruhiro Yamashita (NHO Okayama Medical Center), Eiji Mita (NHO Osaka Medical Center), Taizo Hijioka (NHO Osaka Minami Medical Center), Eiji Mita (NHO Osaka National Hospital), Yoko Nakamura and Yukio Watanabe (NHO Sagamihara National Hospital), Minoru Tomizawa (NHO Shimoshizu National Hospital), Kaname Yoshizawa (NHO Shinshu Ueda Medical Center), Atsushi Naganuma (NHO Takasaki General Medical Center), Masahiro Kikuchi (NHO Tokyo Medical Center), Hiroshi 
Kamitsukasa and Michiyasu Yagura (NHO Tokyo National Hospital), Keisuke Ario (NHO Ureshino Medical Center), Tatsuji Komatsu (NHO Yokohama Medical Center), and Hiroshi Furukawa (NHO Tokyo National Hospital).

\section{Authors' contributions}

$\mathrm{TH}, \mathrm{SO}, \mathrm{HF}$, and $\mathrm{KM}$ conceived and designed the experiments. $\mathrm{TH}, \mathrm{SO}$, and HF performed the experiments. HF analyzed the data. HF, ST, HY, and KM contributed reagents, materials, and analysis tools. TH, SO, HF, ST, HY, and KM wrote the manuscript. The authors read and approved the final manuscript.

\section{Funding}

The work was supported by Grants-in-Aid for Clinical Research from the National Hospital Organization.

\section{Availability of data and materials}

All data are presented in the paper and in the supplementary material.

\section{Ethics approval and consent to participate}

This study protocol was reviewed and approved by the University of Tsukuba Research Ethics Committee, Nagasaki University Research Ethics Committee, and the NHO central Institutional Review Board. Informed consents in writing were obtained from all the participants. The study was performed in accordance with the principles expressed in the Declaration of Helsinki

\section{Consent for publication}

Not required.

\section{Competing interests}

HY was supported by research grants from AbbVie GK. The other authors declare no financial or commercial conflicts of interest.

\section{Author details \\ ${ }^{1}$ Molecular and Genetic Epidemiology Laboratory, Faculty of Medicine, University of Tsukuba, 1-1-1 Tennodai, Tsukuba 305-8575, Japan. 2Department of Nephrology, Ushiku Aiwa General Hospital, 896 Shishiko-cho, Ushiku 300-1296, Japan. ${ }^{3}$ Department of Rheumatology, National Hospital Organization Tokyo National Hospital, 3-1-1 Takeoka, Kiyose 204-8585, Japan. ${ }^{4}$ Clinical Research Center for Allergy and Rheumatology, National Hospital Organization Sagamihara National Hospital, 18-1 Sakuradai, Minami-ku, Sagamihara 252-0392, Japan. ${ }^{5}$ Clinical Research Center, National Hospital Organization Nagasaki Medical Center, 2-1001-1 Kubara, Omura 856-8562, Japan. ${ }^{6}$ Department of Rheumatology, Fukushima Medical University School of Medicine, 1 Hikarigaoka, Fukushima 960-1295, Japan.}

\section{Received: 21 October 2020 Accepted: 15 December 2020}

Published online: 28 January 2021

\section{References}

1. Krawitt EL. Autoimmune hepatitis. N Engl J Med. 2006;354(1):54-66

2. Czaja AJ, Manns MP. Advances in the diagnosis, pathogenesis, and management of autoimmune hepatitis. Gastroenterology. 2010;139(1):58-72 e4.

3. Manns MP, Czaja AJ, Gorham JD, Krawitt EL, Mieli-Vergani G, Vergani D, et al. Diagnosis and management of autoimmune hepatitis. Hepatology. 2010; 51(6):2193-213.

4. Moy L, Levine J. Autoimmune hepatitis: a classic autoimmune liver disease Curr Probl Pediatr Adolesc Health Care. 2014;44(11):341-6.

5. Carbone M, Neuberger JM. Autoimmune liver disease, autoimmunity and liver transplantation. J Hepatol. 2014;60(1):210-23.

6. Wang Q, Yang F, Miao Q, Krawitt EL, Gershwin ME, Ma X. The clinical phenotypes of autoimmune hepatitis: a comprehensive review. J Autoimmun. 2016;66:98-107.

7. Czaja AJ. Global disparities and their implications in the occurrence and outcome of autoimmune hepatitis. Dig Dis Sci. 2017;62(9):2277-92.

8. Yoshizawa K, Joshita S, Matsumoto A, Umemura T, Tanaka E, Morita S, et al. Incidence and prevalence of autoimmune hepatitis in the Ueda area, Japan. Hepatol Res. 2016:46(9):878-83.

9. Lee YM, Teo EK, Ng TM, Khor C, Fock KM. Autoimmune hepatitis in Singapore: a rare syndrome affecting middle-aged women. J Gastroenterol Hepatol. 2001;16(12):1384-9.
10. Mackay IR, Taft LI, Cowling DC. Lupoid hepatitis. Lancet. 1956;271(6957): 1323-6.

11. Mackay IR, Weiden S, Hasker J. Autoimmune hepatitis. Ann N Y Acad Sci. 1965;124(2):767-80.

12. Mackay IR, Taft LI, Cowling DC. Lupoid hepatitis and the hepatic lesions of systemic lupus erythematosus. Lancet. 1959;1(7063):65-9.

13. Migita K, Watanabe $Y$, Jiuchi Y, Nakamura Y, Saito A, Yagura M, et al. Hepatocellular carcinoma and survival in patients with autoimmune hepatitis (Japanese National Hospital Organization-autoimmune hepatitis prospective study). Liver Int. 2012;32(5):837-44.

14. Migita K, Watanabe $Y$, Jiuchi $Y$, Nakamura Y, Saito A, Yagura M, et al. Evaluation of risk factors for the development of cirrhosis in autoimmune hepatitis: Japanese NHO-AlH prospective study. J Gastroenterol. 2011; 46(Suppl 1):56-62

15. Nikias GA, Batts KP, Czaja AJ. The nature and prognostic implications of autoimmune hepatitis with an acute presentation. J Hepatol. 1994;21(5): 866-71.

16. Yamamoto K, Miyake $Y$, Ohira H, Suzuki Y, Zeniya M, Onji M, et al. Prognosis of autoimmune hepatitis showing acute presentation. Hepatol Res. 2013; 43(6):630-8

17. Alvarez F, Berg PA, Bianchi FB, Bianchi L, Burroughs AK, Cancado EL, et al. International autoimmune hepatitis group report: review of criteria for diagnosis of autoimmune hepatitis. J Hepatol. 1999;31(5):929-38.

18. Ishikawa Y, Ikari K, Hashimoto M, Ohmura K, Tanaka M, Ito H, et al. Shared epitope defines distinct associations of cigarette smoking with levels of anticitrullinated protein antibody and rheumatoid factor. Ann Rheum Dis. 2019;78(11):1480-7.

19. Gatselis NK, Zachou K, Koukoulis GK, Dalekos GN. Autoimmune hepatitis, one disease with many faces: etiopathogenetic, clinico-laboratory and histological characteristics. World J Gastroenterol. 2015;21(1):60-83.

20. Efe C, Kav T, Aydin C, Cengiz M, Imga NN, Purnak T, et al. Low serum vitamin D levels are associated with severe histological features and poor response to therapy in patients with autoimmune hepatitis. Dig Dis Sci. 2014;59(12):3035-42.

21. Lin R, Zhou L, Zhang J, Wang B. Abnormal intestinal permeability and microbiota in patients with autoimmune hepatitis. Int J Clin Exp Pathol. 2015;8(5):5153-60

22. Czaja AJ. Autoimmune hepatitis. Part a: pathogenesis. Expert Rev Gastroenterol Hepatol. 2007;1(1):113-28.

23. McCarthy M. The "gender gap" in autoimmune disease. Lancet. 2000; 356(9235):1088.

24. Czaja AJ. Transitioning from idiopathic to explainable autoimmune hepatitis. Dig Dis Sci. 2015;60(10):2881-900

25. Hautekeete ML, Horsmans Y, Van Waeyenberge C, Demanet C, Henrion J, Verbist $L$, et al. HLA association of amoxicillin-clavulanate--induced hepatitis. Gastroenterology. 1999;117(5):1181-6.

26. Kurosaki M, Takagi H, Mori M. HLA-A33/B44/DR6 is highly related to intrahepatic cholestasis induced by tiopronin. Dig Dis Sci. 2000;45(6):1103-8.

27. Hirata K, Takagi H, Yamamoto M, Matsumoto T, Nishiya T, Mori K, et al. Ticlopidine-induced hepatotoxicity is associated with specific human leukocyte antigen genomic subtypes in Japanese patients: a preliminary case-control study. Pharmacogenomics J. 2008;8(1):29-33.

28. Daly AK, Donaldson PT, Bhatnagar P, Shen Y, Pe'er I, Floratos A, et al. HLA$B * 5701$ genotype is a major determinant of drug-induced liver injury due to flucloxacillin. Nat Genet. 2009;41(7):816-9.

29. Parham LR, Briley LP, Li L, Shen J, Newcombe PJ, King KS, et al. Comprehensive genome-wide evaluation of lapatinib-induced liver injury yields a single genetic signal centered on known risk allele HLA-DRB1*07:01. Pharmacogenomics J. 2016;16(2):180-5.

30. Fontana RJ, Cirulli ET, Gu J, Kleiner D, Ostrov D, Phillips E, et al. The role of HLA-A*33:01 in patients with cholestatic hepatitis attributed to terbinafine. J Hepatol. 2018;69(6):1317-25.

31. van Gerven NM, Verwer BJ, Witte BI, van Erpecum KJ, van Buuren HR, Maijers I, et al. Epidemiology and clinical characteristics of autoimmune hepatitis in the Netherlands. Scand J Gastroenterol. 2014;49(10):1245-54.

32. Gronbaek L, Vilstrup $H$, Pedersen $L$, Christensen $K$, Jepsen P. Family occurrence of autoimmune hepatitis: a Danish nationwide registry-based cohort study. J Hepatol. 2018:69(4):873-7.

33. Gronbaek L, Vilstrup $H$, Pedersen $L$, Jepsen P. Extrahepatic autoimmune diseases in patients with autoimmune hepatitis and their relatives: a Danish nationwide cohort study. Liver Int. 2019;39(1):205-14. 
34. de Boer YS, van Gerven NM, Zwiers A, Verwer BJ, van Hoek B, van Erpecum $\mathrm{KJ}$, et al. Genome-wide association study identifies variants associated with autoimmune hepatitis type 1. Gastroenterology. 2014;147(2):443-52 e5.

35. Strettell MD, Donaldson PT, Thomson LJ, Santrach PJ, Moore SB, Czaja AJ, et al. Allelic basis for HLA-encoded susceptibility to type 1 autoimmune hepatitis. Gastroenterology. 1997;112(6):2028-35.

36. Mackay IR, Tait BD. HLA associations with autoimmune-type chronic active hepatitis: identification of B8-DRw3 haplotype by family studies. Gastroenterology. 1980;79(1):95-8.

37. Doherty DG, Donaldson PT, Underhill JA, Farrant JM, Duthie A, Mieli-Vergani $\mathrm{G}$, et al. Allelic sequence variation in the HLA class II genes and proteins in patients with autoimmune hepatitis. Hepatology. 1994;19(3):609-15.

38. Czaja AJ, Carpenter HA, Moore SB. HLA DRB1*13 as a risk factor for type 1 autoimmune hepatitis in north American patients. Dig Dis Sci. 2008;53(2): $522-8$.

39. Umemura T, Katsuyama Y, Yoshizawa K, Kimura T, Joshita S, Komatsu M, et al. Human leukocyte antigen class II haplotypes affect clinical characteristics and progression of type 1 autoimmune hepatitis in Japan. PLoS One. 2014;9(6):e100565.

40. Furumoto Y, Asano T, Sugita T, Abe H, Chuganji Y, Fujiki K, et al. Evaluation of the role of HLA-DR antigens in Japanese type 1 autoimmune hepatitis. BMC Gastroenterol. 2015;15(144):144.

41. Maeda Y, Migita K, Higuchi O, Mukaino A, Furukawa H, Komori A, et al. Association between anti-ganglionic nicotinic acetylcholine receptor (gAChR) antibodies and HLA-DRB1 alleles in the Japanese population. PLoS One. 2016;11(1):e0146048.

42. Oka S, Furukawa H, Yasunami M, Kawasaki A, Nakamura H, Nakamura M, et al. HLA-DRB1 and DQB1 alleles in Japanese type 1 autoimmune hepatitis: the predisposing role of the DR4/DR8 heterozygous genotype. PLoS One. 2017:12(10):e0187325.

43. Seki T, Ota M, Furuta S, Fukushima H, Kondo T, Hino K, et al. HLA class II molecules and autoimmune hepatitis susceptibility in Japanese patients. Gastroenterology. 1992;103(3):1041-7.

44. Yoshizawa K, Ota M, Katsuyama Y, Ichijo T, Matsumoto A, Tanaka E, et al. Genetic analysis of the HLA region of Japanese patients with type 1 autoimmune hepatitis. J Hepatol. 2005;42(4):578-84.

45. Vazquez-Garcia MN, Alaez C, Olivo A, Debaz H, Perez-Luque E, Burguete A, et al. MHC class II sequences of susceptibility and protection in Mexicans with autoimmune hepatitis. J Hepatol. 1998;28(6):985-90.

46. Goldberg AC, Bittencourt PL, Mougin B, Cancado EL, Porta G, Carrilho F, et al. Analysis of HLA haplotypes in autoimmune hepatitis type 1 : identifying the major susceptibility locus. Hum Immunol. 2001;62(2):165-9.

47. Fortes Mdel P, Machado IV, Gil G, Fernandez-Mestre M, Dagher L, Leon RV, et al. Genetic contribution of major histocompatibility complex class ॥ region to type 1 autoimmune hepatitis susceptibility in Venezuela. Liver Int. 2007;27(10):1409-16.

48. Duarte-Rey C, Pardo AL, Rodriguez-Velosa Y, Mantilla RD, Anaya JM, RojasVillarraga A. HLA class II association with autoimmune hepatitis in Latin America: a meta-analysis. Autoimmun Rev. 2009:8(4):325-31.

49. Pando M, Larriba J, Fernandez GC, Fainboim H, Ciocca M, Ramonet M, et al. Pediatric and adult forms of type I autoimmune hepatitis in Argentina: evidence for differential genetic predisposition. Hepatology. 1999;30(6):1374-80.

50. Bittencourt PL, Goldberg AC, Cancado EL, Porta G, Carrilho FJ, Farias AQ et al. Genetic heterogeneity in susceptibility to autoimmune hepatitis types 1 and 2. Am J Gastroenterol. 1999;94(7):1906-13.

51. Czaja AJ, Souto EO, Bittencourt PL, Cancado EL, Porta G, Goldberg AC, et al. Clinical distinctions and pathogenic implications of type 1 autoimmune hepatitis in Brazil and the United States. J Hepatol. 2002;37(3):302-8.

52. Lim YS, Oh HB, Choi SE, Kwon OJ, Heo YS, Lee HC, et al. Susceptibility to type 1 autoimmune hepatitis is associated with shared amino acid sequences at positions 70-74 of the HLA-DRB1 molecule. J Hepatol. 2008; 48(1):133-9.

53. Amarapurkar DN, Patel ND, Amarapurkar AD, Kankonkar SR. HLA genotyping in type-I autoimmune hepatitis in Western India. J Assoc Physicians India. 2003:51:967-9.

54. Kaur N, Minz RW, Anand S, Saikia B, Aggarwal R, Das A, et al. HLA DRB1 alleles discriminate the manifestation of autoimmune hepatitis as type 1 or type 2 in north Indian population. J Clin Exp Hepatol. 2014;4(1):14-8.

55. Baharlou R, Faghihi-Kashani A, Faraji F, Najafi-Samei M, Setareh M, Zamani F, et al. HLA-DRB1 alleles of susceptibility and protection in Iranians with autoimmune hepatitis. Hum Immunol. 2016;77(4):330-5.
56. Hassan N, Siddiqui AR, Abbas Z, Hassan SM, Soomro GB, Mubarak M, et al. Clinical profile and HLA typing of autoimmune hepatitis from Pakistan. Hepat Mon. 2013;13(12):e13598.

57. Yamazaki T, Umemura T, Joshita S, Yoshizawa K, Tanaka E, Ota M. A cis-eQTL of HLA-DPB1 affects susceptibility to type 1 autoimmune hepatitis. Sci Rep. 2018;8(1):11924.

58. Littera R, Chessa L, Onali S, Figorilli F, Lai S, Secci L, et al. Exploring the role of killer cell immunoglobulin-like receptors and their HLA class I ligands in autoimmune hepatitis. PLoS One. 2016;11(1):e0146086.

59. Podhorzer A, Paladino N, Cuarterolo ML, Fainboim HA, Paz S, Theiler G, et al. The early onset of type 1 autoimmune hepatitis has a strong genetic influence: role of HLA and KIR genes. Genes Immun. 2016;17(3):187-92.

60. Umemura T, Joshita S, Yamazaki T, Komatsu M, Katsuyama Y, Yoshizawa K, et al. Genetic association of PTPN22 polymorphisms with autoimmune hepatitis and primary biliary cholangitis in Japan. Sci Rep. 2016;6(29770): 29770.

61. Umemura T, Joshita S, Hamano H, Yoshizawa K, Kawa S, Tanaka E, et al. Association of autoimmune hepatitis with Src homology 2 adaptor protein 3 gene polymorphisms in Japanese patients. J Hum Genet. 2017;62(11):963-7.

62. Higuchi T, Oka S, Furukawa H, Nakamura M, Komori A, Abiru S, et al. Role of deleterious single nucleotide variants in the coding regions of TNFAIP3 for Japanese autoimmune hepatitis with cirrhosis. Sci Rep. 2019;9(1):7925.

63. Migita K, Nakamura M, Abiru S, Jiuchi Y, Nagaoka S, Komori A, et al. Association of STAT4 polymorphisms with susceptibility to type-1 autoimmune hepatitis in the Japanese population. PLoS One. 2013;8(8): e71382.

64. Oka S, Higuchi T, Furukawa H, Nakamura M, Komori A, Abiru S, et al. Association of a single nucleotide polymorphism in TNIP1 with type-1 autoimmune hepatitis in the Japanese population. J Hum Genet. 2018;63(6): 739-44.

65. Higuchi T, Oka S, Furukawa H, Nakamura M, Komori A, Abiru S, et al. Association of a single nucleotide polymorphism upstream of ICOS with Japanese autoimmune hepatitis type 1. J Hum Genet. 2017;62(4):481-4.

66. Agarwal K, Czaja AJ, Jones DE, Donaldson PT. Cytotoxic T lymphocyte antigen-4 (CTLA-4) gene polymorphisms and susceptibility to type 1 autoimmune hepatitis. Hepatology. 2000;31(1):49-53.

67. Djilali-Saiah I, Ouellette P, Caillat-Zucman S, Debray D, Kohn Jl, Alvarez F. CTLA-4/CD 28 region polymorphisms in children from families with autoimmune hepatitis. Hum Immunol. 2001;62(12):1356-62.

68. Hiraide A, Imazeki F, Yokosuka O, Kanda T, Kojima H, Fukai K, et al. Fas polymorphisms influence susceptibility to autoimmune hepatitis. Am J Gastroenterol. 2005;100(6):1322-9.

69. Agarwal K, Czaja AJ, Donaldson PT. A functional Fas promoter polymorphism is associated with a severe phenotype in type 1 autoimmune hepatitis characterized by early development of cirrhosis. Tissue Antigens. 2007;69(3):227-35

70. Cookson S, Constantini PK, Clare M, Underhill JA, Bernal W, Czaja AJ, et al. Frequency and nature of cytokine gene polymorphisms in type 1 autoimmune hepatitis. Hepatology. 1999;30(4):851-6.

71. Czaja AJ, Cookson S, Constantini PK, Clare M, Underhill JA, Donaldson PT. Cytokine polymorphisms associated with clinical features and treatment outcome in type 1 autoimmune hepatitis. Gastroenterology. 1999;117(3): 645-52.

72. Kawabata Y, Ikegami H, Kawaguchi Y, Fujisawa T, Shintani M, Ono M, et al. Asian-specific HLA haplotypes reveal heterogeneity of the contribution of HLA-DR and -DQ haplotypes to susceptibility to type 1 diabetes. Diabetes. 2002;51(2):545-51.

73. Czaja AJ, Carpenter HA, Santrach PJ, Moore SB. Significance of HLA DR4 in type 1 autoimmune hepatitis. Gastroenterology. 1993;105(5):1502-7.

74. Furukawa H, Oka S, Tsuchiya N, Shimada K, Hashimoto A, Tohma S, et al. The role of common protective alleles HLA-DRB1*13 among systemic autoimmune diseases. Genes Immun. 2017;18(1):1-7.

75. Djilali-Saiah I, Fakhfakh A, Louafi H, Caillat-Zucman S, Debray D, Alvarez F. HLA class II influences humoral autoimmunity in patients with type 2 autoimmune hepatitis. J Hepatol. 2006;45(6):844-50.

76. Thomas R, Thio CL, Apps R, Qi Y, Gao X, Marti D, et al. A novel variant marking HLA-DP expression levels predicts recovery from hepatitis $B$ virus infection. J Virol. 2012:86(12):6979-85.

77. Petersdorf EW, Malkki M, O'HUigin C, Carrington M, Gooley T, Haagenson MD, et al. High HLA-DP expression and graft-versus-host disease. N Engl J Med. 2015;373(7):599-609. 
78. Suzuki S, Ranade S, Osaki K, Ito S, Shigenari A, Ohnuki Y, et al. Reference grade characterization of polymorphisms in full-length HLA class I and II genes with short-read sequencing on the ION PGM system and long-reads generated by single molecule, real-time sequencing on the PacBio platform. Front Immunol. 2018;9(2294):2294.

79. Kusano S, Kukimoto-Niino M, Satta Y, Ohsawa N, Uchikubo-Kamo T, Wakiyama $M$, et al. Structural basis for the specific recognition of the major antigenic peptide from the Japanese cedar pollen allergen cry j 1 by HLADP5. J Mol Biol. 2014:426(17):3016-27.

80. Migita K, Jiuchi Y, Furukawa H, Nakamura M, Komori A, Yasunami M, et al. Lack of association between the CARD10 rs6000782 polymorphism and type 1 autoimmune hepatitis in a Japanese population. BMC Res Notes. 2015;8(777):777.

81. Blonska M, Lin X. NF-kappaB signaling pathways regulated by CARMA family of scaffold proteins. Cell Res. 2011:21(1):55-70.

82. Dieli-Crimi $R$, Cenit MC, Nunez $C$. The genetics of celiac disease: a comprehensive review of clinical implications. J Autoimmun. 2015;64:26-41.

83. Zhernakova A, Elbers CC, Ferwerda B, Romanos J, Trynka G, Dubois PC, et al. Evolutionary and functional analysis of celiac risk loci reveals $\mathrm{SH} 2 \mathrm{~B} 3$ as a protective factor against bacterial infection. Am J Hum Genet. 2010;86(6): 970-7.

84. van Heel DA, Franke L, Hunt KA, Gwilliam R, Zhernakova A, Inouye M, et al. A genome-wide association study for celiac disease identifies risk variants in the region harboring IL2 and IL21. Nat Genet. 2007;39(7):827-9.

85. Dubois PC, Trynka G, Franke L, Hunt KA, Romanos J, Curtotti A, et al. Multiple common variants for celiac disease influencing immune gene expression. Nat Genet. 2010;42(4):295-302.

86. Dong C, Juedes AE, Temann UA, Shresta S, Allison JP, Ruddle NH, et al. ICOS co-stimulatory receptor is essential for T-cell activation and function. Nature. 2001:409(6816):97-101.

87. Bittencourt PL, Palacios SA, Cancado EL, Porta G, Carrilho FJ, Laudanna AA, et al. Cytotoxic T lymphocyte antigen-4 gene polymorphisms do not confer susceptibility to autoimmune hepatitis types 1 and 2 in Brazil. Am J Gastroenterol. 2003;98(7):1616-20.

88. Umemura T, Ota M, Yoshizawa K, Katsuyama Y, Ichijo T, Tanaka E, et al. Association of cytotoxic T-lymphocyte antigen 4 gene polymorphisms with type 1 autoimmune hepatitis in Japanese. Hepatol Res. 2008;38(7):689-95.

89. Eskandari-Nasab E, Tahmasebi A, Hashemi M. Meta-analysis: the relationship between CTLA-4 +49 a/G polymorphism and primary biliary cirrhosis and type I autoimmune hepatitis. Immunol Invest. 2015;44(4):331-48.

90. Tagawa Y, Kakuta S, Iwakura Y. Involvement of Fas/Fas ligand systemmediated apoptosis in the development of concanavalin A-induced hepatitis. Eur J Immunol. 1998;28(12):4105-13.

91. Furukawa H, Kitazawa H, Kaneko I, Matsubara M, Nose M, Ono M. Role of 2B4-mediated signals in the pathogenesis of a murine hepatitis model independent of Fas and Valpha14 NKT cells. Immunology. 2008;128(1 Suppl):e151-8

92. Pociot F, Briant L, Jongeneel CV, Molvig J, Worsaae H, Abbal M, et al. Association of tumor necrosis factor (TNF) and class II major histocompatibility complex alleles with the secretion of TNF-alpha and TNFbeta by human mononuclear cells: a possible link to insulin-dependent diabetes mellitus. Eur J Immunol. 1993;23(1):224-31.

93. Assis DN, Takahashi H, Leng L, Zeniya M, Boyer JL, Bucala R. A macrophage migration inhibitory factor polymorphism is associated with autoimmune hepatitis severity in US and Japanese patients. Dig Dis Sci. 2016;61(12): 3506-12.

94. Mansour Al, Behairy OG, Abd Almonaem ER, Abd-Rabuh RM, Ahmed IAE Association of interleukin (IL)-4 variable number of tandem repeats (VNTRs) and IL-4-590 promoter polymorphisms with susceptibility to pediatric autoimmune hepatitis type 1. Cytokine. 2018;110:243-7.

95. Liang YL, Wu H, Shen X, Li PQ, Yang XQ, Liang L, et al. Association of STAT4 rs 7574865 polymorphism with autoimmune diseases: a meta-analysis. Mol Biol Rep. 2012;39(9):8873-82

96. Gao B. Cytokines, STATs and liver disease. Cell Mol Immunol. 2005:2(2): 92-100

97. Fan $L$, Tu X, Zhu $Y$, Zhou L, Pfeiffer $T$, Feltens $R$, et al. Genetic association of vitamin $D$ receptor polymorphisms with autoimmune hepatitis and primary biliary cirrhosis in the Chinese. J Gastroenterol Hepatol. 2005;20(2):249-55.

98. Vogel A, Strassburg CP, Manns MP. Genetic association of vitamin D receptor polymorphisms with primary biliary cirrhosis and autoimmune hepatitis. Hepatology. 2002;35(1):126-31.
99. Panierakis C, Goulielmos G, Mamoulakis D, Petraki E, Papavasiliou E, Galanakis E. Vitamin D receptor gene polymorphisms and susceptibility to type 1 diabetes in Crete, Greece. Clin Immunol. 2009;133(2):276-81.

100. Smolders J, Damoiseaux J, Menheere P, Tervaert JW, Hupperts R. Association study on two vitamin $D$ receptor gene polymorphisms and vitamin D metabolites in multiple sclerosis. Ann N Y Acad Sci. 2009;1173:515-20.

101. Jeffery LE, Burke F, Mura M, Zheng Y, Qureshi OS, Hewison M, et al. 1,25Dihydroxyvitamin D3 and IL-2 combine to inhibit T cell production of inflammatory cytokines and promote development of regulatory $T$ cells expressing CTLA-4 and FoxP3. J Immunol. 2009;183(9):5458-67.

102. Chen S, Zhao W, Tan W, Luo X, Dan Y, You Z, et al. Association of TBX21 promoter polymorphisms with type 1 autoimmune hepatitis in a Chinese population. Hum Immunol. 2011;72(1):69-73.

103. Paladino N, Flores AC, Fainboim H, Schroder T, Cuarterolo M, Lezama C, et al. The most severe forms of type I autoimmune hepatitis are associated with genetically determined levels of TGF-beta1. Clin Immunol. 2010;134(3): 305-12.

104. Nair RP, Duffin KC, Helms C, Ding J, Stuart PE, Goldgar D, et al. Genomewide scan reveals association of psoriasis with IL-23 and NF-kappaB pathways. Nat Genet. 2009;41(2):199-204.

105. Kawasaki A, Ito I, Ito S, Hayashi T, Goto D, Matsumoto I, et al. Association of TNFAIP3 polymorphism with susceptibility to systemic lupus erythematosus in a Japanese population. J Biomed Biotechnol. 2010;2010(207578):207578.

106. Zhou Q, Wang H, Schwartz DM, Stoffels M, Park YH, Zhang Y, et al. Loss-offunction mutations in TNFAIP3 leading to A20 haploinsufficiency cause an early-onset autoinflammatory disease. Nat Genet. 2016;48(1):67-73.

107. Shigemura T, Kaneko N, Kobayashi N, Kobayashi K, Takeuchi Y, Nakano N, et al. Novel heterozygous C243Y A20/TNFAIP3 gene mutation is responsible for chronic inflammation in autosomal-dominant Behcet's disease. RMD Open. 2016;2(1):e000223.

108. Aksentijevich I, Zhou Q. NF-kappaB pathway in autoinflammatory diseases: dysregulation of protein modifications by ubiquitin defines a new category of autoinflammatory diseases. Front Immunol. 2017:8(399):399.

109. Wang X, Ai L, Xu Q, Wu C, Chen Z, Su D, et al. A20 attenuates liver fibrosis in NAFLD and inhibits inflammation responses. Inflammation. 2017;40(3): $840-8$.

110. Jimenez-Sousa MA, Berenguer J, Fernandez-Rodriguez A, Medrano LM, Aldamiz-Echevarria T, Perez-Latorre L, et al. Genetic variants upstream of TNFAIP3 in the 6q23 region are associated with liver disease severity in HIV/ HCV-coinfected patients: a cross-sectional study. Infect Genet Evol. 2019;67: $112-20$.

111. Han JW, Zheng HF, Cui Y, Sun LD, Ye DQ, Hu Z, et al. Genome-wide association study in a Chinese Han population identifies nine new susceptibility loci for systemic lupus erythematosus. Nat Genet. 2009;41(11): $1234-7$

112. Gateva V, Sandling JK, Hom G, Taylor KE, Chung SA, Sun X, et al. A largescale replication study identifies TNIP1, PRDM1, JAZF1, UHRF1BP1 and IL10 as risk loci for systemic lupus erythematosus. Nat Genet. 2009;41(11):122833

113. Kawasaki A, Ito S, Furukawa H, Hayashi T, Goto D, Matsumoto I, et al. Association of TNFAIP3 interacting protein 1, TNIP1 with systemic lupus erythematosus in a Japanese population: a case-control association study. Arthritis Res Ther. 2010;12(5):R174.

114. Quintero OL, Amador-Patarroyo MJ, Montoya-Ortiz G, Rojas-Villarraga A, Anaya JM. Autoimmune disease and gender: plausible mechanisms for the female predominance of autoimmunity. J Autoimmun. 2012;38(2-3):J109-19.

115. Sasaki N, Yamauchi K, Sato R, Masuda T, Sawai T, Inoue H. Klinefelter's syndrome associated with systemic lupus erythematosus and autoimmune hepatitis. Mod Rheumatol. 2006:16(5):305-8.

116. Okada Y, Wu D, Trynka G, Raj T, Terao C, Ikari K, et al. Genetics of rheumatoid arthritis contributes to biology and drug discovery. Nature. 2014:506(7488):376-81.

117. Sirota M, Schaub MA, Batzoglou S, Robinson WH, Butte AJ. Autoimmune disease classification by inverse association with SNP alleles. PLoS Genet. 2009;5(12):e1000792.

118. Strassburg CP, Manns MP. Treatment of autoimmune hepatitis. Semin Liver Dis. 2009;29(3):273-85

\section{Publisher's Note}

Springer Nature remains neutral with regard to jurisdictional claims in published maps and institutional affiliations. 